\title{
Platelet-Activating Factor Antagonists Decrease Follicular Dendritic-Cell Stimulation of Human B Lymphocytes
}

\author{
Isaac Halickman, MD; Yolande Bastien, MS; Qianli Zhuang, MD, PhD; \\ Monty B. Mazer; Baruch Toledano, MD; Bruce D. Mazer, MD
}

\begin{abstract}
Both B-lymphoblastoid cell lines and tonsillar B lymphocytes express receptors for platelet-activating factor (PAF). In lymph node germinal centres, B lymphocytes interact with follicular dendritic cells (FDCs), which present antigen-containing immune complexes to B lymphocytes. FDCs have phenotypic features that are similar to those of stromal cells and monocytes and may therefore be a source of lipid mediators. In this study, we evaluated the effects of the PAF antagonist WEB 2170 on the activation of tonsillar B lymphocytes by FDCs. FDCs were isolated from tonsils by Bovine Serum Albumin (BSA) gradient centrifugation. After being cultured for 6 to 10 days, they were incubated with freshly isolated $B$ cells in the presence or absence of the specific PAF receptor antagonist WEB 2170. B-lymphocyte proliferation was assessed by $\left[{ }^{3} \mathrm{H}\right]$-thymidine incorporation, and immunoglobulin $(\mathrm{Ig}) \mathrm{G}$ and $\mathrm{IgM}$ secretion was assessed by enzyme-linked immunosorbent assay (ELISA). WEB $2170\left(10^{-6}\right.$ to $\left.10^{-8} \mathrm{M}\right)$ inhibited $\left[{ }^{3} \mathrm{H}\right]-$ thymidine incorporation by up to $35 \% \pm 3 \%$. Moreover, the secretion of $\lg G$ and $\operatorname{lgM}$ was inhibited by up to $50 \%$ by WEB 2170 concentrations ranging from $10^{-6}$ to $10^{-8} \mathrm{M}$. There was no evidence of toxicity by trypan blue staining, and the addition of WEB 2170 to B cells in the absence of FDCs did not inhibit the spontaneous production of IgG or IgM. The effect of the PAF antagonist is primarily on B lymphocytes, as reverse transcription polymerase chain reaction detected little PAF receptor messenger ribonucleic acid (mRNA) from FDCs. These data suggest that endogenous production of PAF may be important in the interaction of B lymphocytes with FDCs.
\end{abstract}

Antigen presentation is a crucial part of any immune response. Antigen-presenting cells coordinate the interaction between antigens and effector cells such as T lymphocytes and B lymphocytes. Follicular dendritic cells (FDCs) are specific antigen-presenting cells that interact with B lymphocytes. These cells, found in lymph node germinal

I. Halickman, Y. Bastien, Q. Zhuang, M. B. Mazer, B. Toledano, B. D. Mazer-Meakins-Christie Laboratories and the McGill University/Montreal Children's Hospital Research Institute, Montreal, Quebec

Correspondence to: Dr. Bruce Mazer, 3626 St. Urbain, Montreal, QC Canada, H2X 2P2 email:

Bruce.Mazer@McGill.ca centres (GCs), trap antigens in immune complexes and present them to surface immunoglobulin receptors on $\mathrm{B}$ lymphocytes. This leads to the interaction of B lymphocytes with antigens and is a crucial step in the generation of long-lasting antibody responses and memory B lymphocytes. ${ }^{1}$ However, FDCs provide additional signals via adhesion receptors and through a network of channels that rescue B lymphocytes from apoptosis, allowing them to proliferate and ultimately secrete immunoglobulin. These points of attachment include adhesion molecules such as VLA-4, the complement receptor CR2, and other molecules potentially. ${ }^{2}$ There are also multiple tight conjunction links between the B lymphocytes and 
the FDCs, and it is presumed that molecules such as soluble mediators or lipids pass through these tight junctions and enhance the communication between B lymphocytes and the FDCs. ${ }^{3}$

The lineage of FDCs is unclear. They may arise from bone marrow stem cells similar to those that interact with B lymphocytes in their early development. However, a second possible lineage is monocyte or macrophage lineage, similar to the lineage of dendritic cells that interact with $\mathrm{T}$ lymphocytes. ${ }^{4}$ This confusion persists because FDCs have both features of stromal cells and features of monocytes such as CD14 and adhesion molecules such as VLA-4. 5,6

We have determined that platelet-activating factor (PAF), a potent lipid mediator, can abrogate apoptosis and elevate immunoglobulin levels in Blymphoblastoid cell lines. ${ }^{7,8}$ More recently, we demonstrated that GC-like B lymphocytes isolated from tonsils had a high level of PAF receptor (PAFR) messenger ribonucleic acid (mRNA) expression when compared to more mature mantle-zone B lymphocytes and that PAF induced tonsillar B lymphocytes to produce the cytokine interleukin-4 (IL-4). ${ }^{9}$ Finally, following antigen receptor ligation, PAFR was irreversibly down-regulated on immortalized B lymphocytes, suggesting that the optimal time for a B lymphocyte to respond to PAF is upon entering the GC. ${ }^{10}$ The source for PAF in the lymph node that might stimulate GC B lymphocytes is unknown. Because both cells of monocyte or stromal cell origin have been shown to produce lipid mediators, ${ }^{11-14}$ it is possible that mediators such as PAF may assist FDCs in attracting or activating B lymphocytes. In these studies, we determined that a pharmacologic antagonist of PAF, WEB 2170, could alter the ability of FDCs to stimulate proliferation and immunoglobulin secretion in B lymphocytes.

\section{Methods}

\section{Media and Reagents}

RPMI-1640 was purchased from Life Technologies (Burlington, $\mathrm{ON}$ ) and was supplemented with $10 \%$ fetal bovine serum (Hyclone, Logan, UT) and with penicillin $(50 \mathrm{U} / \mathrm{mL})$, streptomycin
(50 $\mu \mathrm{g} / \mathrm{mL})$, L-glutamine $(10 \mu \mathrm{g} / \mathrm{mL})$, and sodium pyruvate $(1 \mu \mathrm{g} / \mathrm{mL})$ (all purchased from Life Technologies). PAF (1-alkyl-2-acetyl-sn-3-glycerophosphocholine, C-16) was purchased from BIOMOL International (Plymouth Meeting, PA). The specific PAFR antagonist, WEB 2170, was courtesy of Boehringer-Ingelheim (Ingelheim-amRhein, Germany).

\section{Fractionation of B Lymphocytes and FDCs from Tonsils}

Human FDCs were isolated from tonsils excised surgically for routine indications. After mincing, the mononuclear cell fraction was isolated by Ficoll-Paque density centrifugation (Pharmacia, Toronto, ON). Tonsillar mononuclear cells were then separated into T- and B-lymphocyte fractions by rosetting once with neuraminidase-treated sheep red blood cells, followed by a second FicollPaque gradient. Monocytes were removed by adherence depletion. The B-lymphocyte fraction was subsequently applied to a $1.5 \%$ albumin gradient and centrifuged for 5 minutes at $400 \mathrm{rpm}$ at $4^{\circ} \mathrm{C}$, with no brake. The pellet contained primarily FDCs and some associated B lymphocytes. FDCs were plated in six well plates in complete medium; after 3 days, the nonadherent B cells were removed, and the remaining FDCs were kept in culture. They were fed by the addition of complete medium twice weekly prior to use.

\section{Cell Culture}

FDCs were maintained in six well plates until use, trypsinized, counted, and resuspended in complete medium at $4 \times 10^{5}$ per millilitre. B lymphocytes were isolated from tonsils as described above and were resuspended in complete medium at $0.5 \times 10^{6}$ per millilitre. To obtain low-density GC-like cells, mixed B lymphocytes were applied to Percoll (Amersham Biotec, Piscattawa, NJ) gradients, and the fraction obtained between $30 \%$ to $50 \%$ Percoll was collected. B lymphocytes and FDCs were cultured together in complete medium, with or without the addition of the PAF antagonist WEB 2170 in 96 well plates. 


\section{[3H]-Thymidine Incorporation}

B lymphocytes and FDCs were cultured together for 90 to 114 hours at $37^{\circ} \mathrm{C}$, in $5 \%$ carbon dioxide. $\left[{ }^{3} \mathrm{H}\right]$-Thymidine was then added $(1 \mu \mathrm{CU}$ per well), and the cells were incubated an additional 6 hours. The cells were harvested by water lysis (PHD Cell Harvester, Cambridge Technology, Cambridge MA), and $\left[{ }^{3} \mathrm{H}\right]$-thymidine incorporation was measured by a liquid scintillation betacounter (Wallac, Gaithersburg, MD).

\section{Measurement of Immunoglobulins $M$ and $G$}

Cell culture supernatants were harvested after 7 days, and immunoglobulin (Ig) G and IgM were measured by enzyme-linked immunosorbent assay (ELISA), as described. ${ }^{7}$ Briefly, supernatants from cell culture or standard sera (Binding Site, Birmingham, UK) were applied at appropriate dilutions on Nunclon round-bottom ELISA plates (Nunc A/S, Roskilde, Denmark) precoated with goat antihuman IgM or IgG (Biosource, Camarillo, CA) and blocked with $1 \%$ Bovine serum albumin (BSA) in a tris(hydroxymethyl)aminomethane (TRIS)-based buffer ( $\mathrm{pH}, 7.2)$, then incubated overnight at $4^{\circ} \mathrm{C}$. After extensive washing with water, the appropriate dilution of the alkaline phosphatase conjugated goat antihuman second antibody (Biosource) was added, and the plates were incubated for 1 hour at $37^{\circ} \mathrm{C}$ and then equilibrated to room temperature. After extensive washing, the plates were developed with alkaline phosphatase substrate 105 (Sigma Corp., St. Louis, MO) and read at wavelength 405 (Anthos 2001 ELISA Reader, Anthos Labtec Instruments, Salzburg, Germany).

\section{Detection of PAFR by Polymerase Chain Reaction}

Total cellular ribonucleic acid (RNA) was extracted from $15 \times 10^{6}$ cells with TRIzol (Life Technologies) with the modifications for reverse transcriptase polymerase chain reaction (RT-PCR). RNA was dissolved in DEPC $\mathrm{H}_{2} \mathrm{O}$ and stored at $-80^{\circ} \mathrm{C}$ until use. RT-PCR was performed for 30 cycles in a Hybaid Omnigene thermal cycler (Hybaid Ltd., Middlesex, UK) using the PAFR-specific primers 5'-CGGACATGCTCTTCTTGATCA-3' (sense) and 5'-GTCTAAGACACAGTTGGTGCTA-3' (antisense), as described. ${ }^{11}$ Polymerase chain reaction (PCR) products were applied to a $2 \%$ agarose gel, stained with ethidium bromide, and visualized under ultraviolet (UV) light.

\section{Results}

\section{Isolation and Identification of FDCs}

FDCs were purified from tonsils and maintained in tissue culture for at least 6 days prior to use. This ensured that most FDC-associated B lymphocytes from the original tonsil were removed. The FDCs exhibited the typical morphologic appearance of spindle-shaped adherent cells in culture and stained negatively for CD20 and CD3 and positively for CD14 and VLA-4 by flow cytometry (data not shown). In addition, viability testing indicated that by day 6 , all B cells had died in culture, without added B-cell mitogens, but the FDCs remained viable and multiplied steadily.

\section{Effect of PAF Antagonists on Cell Proliferation}

FDCs maintain B-cell growth in culture, even without the addition of mitogens. ${ }^{15}$ We cultured purified FDCs with freshly isolated B lymphocytes and assessed cellular proliferation by $\left[{ }^{3} \mathrm{H}\right]-$ thymidine incorporation following 120 hours of culture. In the absence of FDCs, B lymphocytes alone did not incorporate $\left[{ }^{3} \mathrm{H}\right]$-thymidine significantly whereas FDCs alone did show some baseline $\left[{ }^{3} \mathrm{H}\right]$-thymidine incorporation (Figure 1, upper panel). Treatment with mitomycin $\mathrm{C}$ (15 $\mu \mathrm{g} / \mathrm{mL}$ for 2 hours) did not significantly decrease background thymidine incorporation by FDCs. The combination of mixed tonsillar B lymphocytes and FDCs caused morphologically larger B-lymphocyte clusters (data not shown) 
and significantly greater uptake of $\left[{ }^{3} \mathrm{H}\right]-$ thymidine than either of the two cell types alone (see Figure 1, upper panel). Addition of the PAF antagonist WEB $2170\left(10^{-6}\right.$ to $\left.10^{-8} \mathrm{M}\right)$ to mixed B lymphocytes consistently diminished cell proliferation (see Figure 1, upper panel). Significant inhibition was also achieved when we separated tonsillar B lymphocytes into characterized fractions by Percoll density centrifugation. The lowdensity Percoll fraction contains cells that have the highest PAFR expression, based on mRNA and functional studies. ${ }^{9}$ Culturing of the lowdensity fraction and FDCs also led to significant increases in $\left[{ }^{3} \mathrm{H}\right]$-thymidine incorporation, which was inhibited $35 \% \pm 3 \%$ by WEB 2170 (see Figure 1, lower panel). However, the other fractions resulting from Percoll density separation (medium and high density) were not significantly affected by the addition of WEB 2170 (data not shown). No toxicity resulted from WEB 2170 administration, as was demonstrated by direct observation of the cultures and by trypan blue staining. Inhibition was not found with WEB 2170 doses $\leq 10^{-10} \mathrm{M}$ (data not shown).

\section{Effect of PAF Antagonists on Production of Immunoglobulin}

Maintenance of B lymphocytes in culture by FDCs leads to an increase in Ig production. ${ }^{16}$ To assess if PAF antagonists would decrease the ability of FDCs to sustain Ig production, we added WEB 2170 to B lymphocytes, FDCs, or the combination of B lymphocytes and FDCs at the initiation of culture, and supernatants were harvested after 7 days of incubation. In keeping with the purity of our FDCs, no IgG or IgM was detected from these cells in culture alone (data not shown). B lymphocytes alone made detectable amounts of Ig, but the combination of FDCs and B lymphocytes produced three to five times more $\operatorname{IgM}(91 \pm 68 \mathrm{ng} / \mathrm{mL}$ vs $308 \pm 175 \mathrm{ng} / \mathrm{mL})$ and $\mathrm{IgG}(220 \pm 72 \mathrm{ng} / \mathrm{mL}$ vs $875 \pm 448 \mathrm{ng} / \mathrm{mL}$ ). The addition of WEB 2170 at doses of $10^{-8}$ to $10^{-6} \mathrm{M}$ led to a significant inhibition of Ig production, from 44 to $75 \%$ of the baseline IgM or IgG production (Figure 2).

\section{Detection of PAFR mRNA from FDCs, by PCR}

We have demonstrated that both B-lymphocyte cell lines and freshly isolated tonsillar B lymphocytes express high levels of PAFR mRNA ${ }^{9}$ and that stimulation of the PAFR leads to demonstrable intracellular signalling and increased Ig production. ${ }^{8,9}$ In addition, PAF rescued B-lymphocyte cell lines from apoptosis $^{7,17}$ and induced expression of IL-4 and IL-13 mRNA in freshly isolated B lymphocytes. ${ }^{9}$ Radiolabelled WEB 2170 was taken up on PAFR expressed by B lymphocytes and B-lymphocyte cell lines..$^{10}$ However, it is unknown whether FDCs express PAFR and would thus be directly affected by the PAF antagonist. RNA was extracted from cultured B lymphocytes and cultured FDCs that were morphologically free of contaminating B lymphocytes, as detailed above. The results of the PCR analysis are shown in Figure 3. Although PAFR mRNA was detectable from FDCs (see Figure 3, lane 3), only a small amount was present as compared with that detected from B lymphocytes (see Figure 3 , lane 4). This suggests that the predominant action of WEB 2170 is on B-lymphocyte PAFR.

\section{Discussion}

The interaction between FDCs and B lymphocytes is a crucial one for the generation of highaffinity antibody secreting memory B lymphocytes. ${ }^{18-21}$ FDCs provide crucial elements for B-lymphocyte survival in the GC of lymph nodes, such as antigen and accessory molecules. As antigen-presenting cells, FDCs trap IgG-coated antigens, primarily in immune complexes, and present them on their surfaces for long durations. ${ }^{1} \mathrm{~B}$ lymphocytes that have a high affinity for the antigen are selected, and these are allowed to further develop in a process known as affinity maturation. The surfaces of FDCs display other accessory molecules, including complement receptors and adhesion molecules such as VLA-4, that provide stimulatory signals for B-cell proliferation and Ig production. In addition, FDCs can rescue B lymphocytes from apoptosis, independently of adhesion molecules or CD40 ligation. ${ }^{22,23}$ 

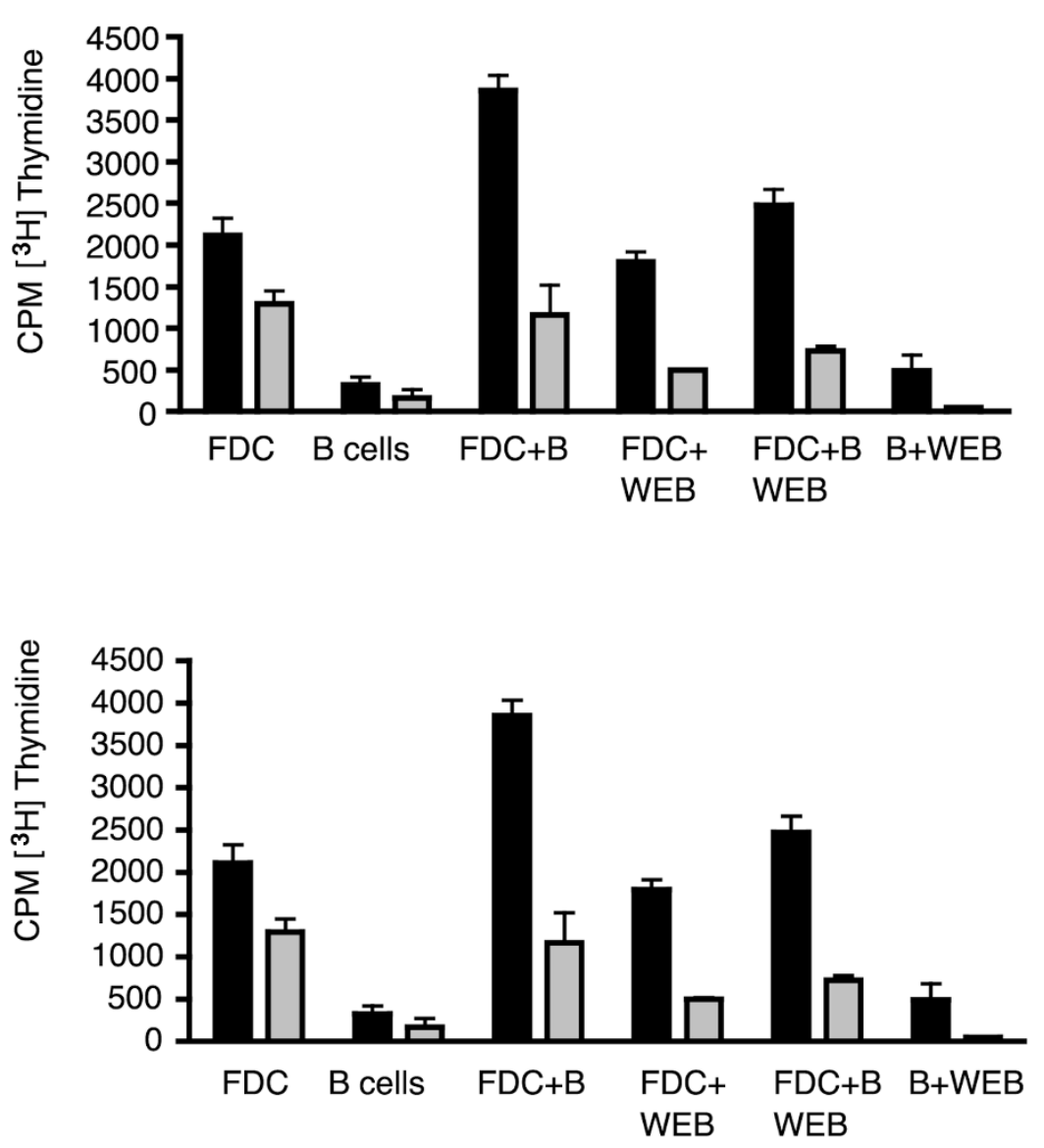

Figure 1 WEB 2170 diminished the proliferation of $B$ lymphocytes. Tonsillar B lymphocytes were cultured with isolated follicular dendritic cells for 120 hours with and without WEB $2170\left(10^{-8} \mathrm{M}\right)$. After 114 to 116 hours, $\left[{ }^{3} \mathrm{H}\right]$-thymidine $(1.0 \mu \mathrm{CU}$ per well) was added, and the cells were harvested 4 to 6 hours later. The histograms represent cell proliferation as expressed by incorporation of $\left[{ }^{3} \mathrm{H}\right]-$ thymidine. Upper panel shows assessment of mixed tonsillar B lymphocytes $(n=4)$; lower panel shows assessment of low-density tonsillar B lymphocytes The gray and black bars represent two separate experiments performed in triplicate $(n=2)$.
We have shown that B lymphocytes from tonsils express receptors for the potent ether lipid PAF. The highest level of PAFR mRNA expression was found in the low- and medium-density layers from Percoll-fractionated subsets of B lymphocytes, and the addition of PAF to the low-density fraction engendered the highest increases in intracellular calcium and in the production of Ig. ${ }^{9}$ These two populations represent GC B lymphocytes as well as rapidly proliferating centroblasts and centrocytes. Because FDCs are potentially of hematopoietic-cell origin, related to monocytes or macrophages, we hypothesized that they might be sources of lipid mediators such as PAF. ${ }^{24}$ Indeed, early work on FDCs indicated a possible role for prostaglandins in their function. ${ }^{12}$ In these preliminary studies, we tested whether the PAF antagonist WEB 2170 could inhibit FDC-mediated stimulation of B lymphocytes.

FDCs support B-lymphocyte growth and the synthesis of Ig without additional mitogens. ${ }^{19}$ This allowed direct observation of the role of the PAF antagonist. The high-affinity water-soluble PAF antagonist WEB $2170^{25,26}$ clearly had an effect, decreasing cell proliferation (as measured by $\left[{ }^{3} \mathrm{H}\right]-$ thymidine incorporation) by $35 \%$ and the production of $\operatorname{IgM}$ and $\mathrm{IgG}$ by the isolated tonsillar cells by 45 to $75 \%$. This was seen over doses ranging from $10^{-6}$ to $10^{-8} \mathrm{M}$; doses exceeding this were ineffective. High exogenous doses of a pharmacologic PAF antagonist are probably needed to saturate the PAFR sites on B lymphocytes and to overcome the large local production known to occur where lipid mediators are synthesized. This dose is comparable to the effective dose for inhibiting PAF-mediated elevation of free cystolic calcium $\left(\mathrm{Ca}^{2+}\right)$ concentrations $\left(\left[\mathrm{Ca}^{2+}\right] \mathrm{i}\right)$ or in vitro Ig production..$^{27,28}$ Although PAF antagonists had a consistent effect in FDC B-lymphocyte cultures, it is not surprising that they did not completely inhibit $\left[{ }^{3} \mathrm{H}\right]$-thymidine incorporation or Ig production. First, the source of Ig secretion from cultured ton- 

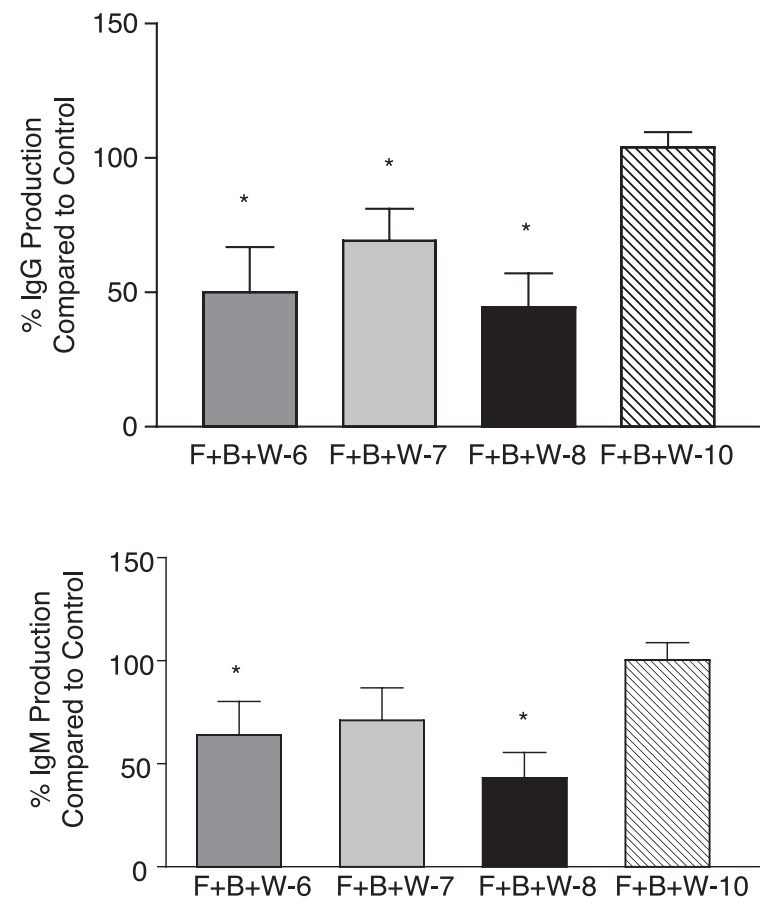

Figure 2 WEB 2170 diminished the production of immunoglobulin (Ig) in cultures of mixed follicular dendritic cells (FDCs) and B lymphocytes. Mixed tonsillar B lymphocytes and FDCs were cultured together with or without the indicated concentrations of WEB 2170 in 24 well plates for 7 days. On day 7, supernatants were harvested and used for measuring total IgG or IgM. The histograms indicate the percentage decrease in $\operatorname{IgG}(\mathrm{A})$ and $\operatorname{IgM}(\mathrm{B})$ from cultures untreated by WEB 2170 (values are indicated in the text) $(n=5) . \mathrm{B}=\mathrm{B}$ lymphocytes; $\mathrm{F}=\mathrm{FDCs} ; \mathrm{W}=\mathrm{WEB} 2170 .{ }^{*} p<.05$.

sillar cells includes a small number of plasma cells that secrete immunoglobulins, as well as other mature B cells that may die in culture and release a basal level of IgG and IgM. Second, the interaction of FDCs and B lymphocytes is mediated by numerous adhesion molecules, chemokines, and other mediators ${ }^{18,29}$; these studies indicate that PAF may be an important contributor to this process.

The effect of the PAF antagonist WEB 2170 is most likely directly on B lymphocytes and not on the FDCs themselves. Whereas monocytes and other dendritic cells such as those derived from $\mathrm{CD} 34^{+}$peripheral blood cells have been shown to express high levels of PAFR mRNA, ${ }^{30}$ FDCs expressed little PAFR mRNA. Expression of PAFR mRNA was low as compared to B lymphocytes

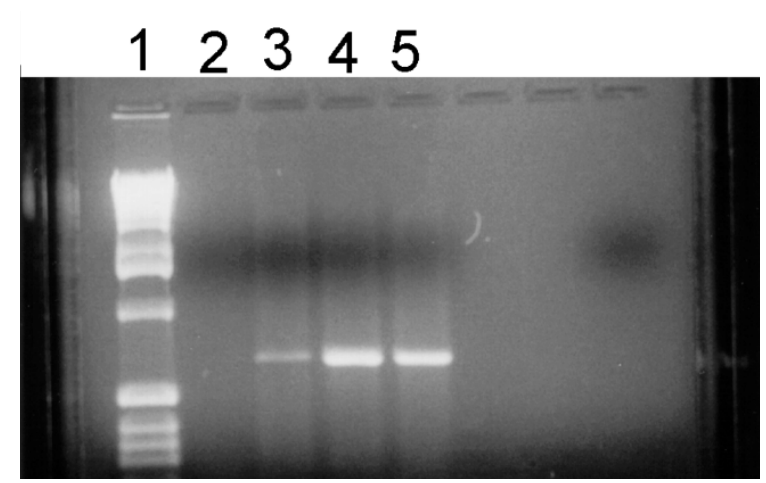

Figure 3 Results of reverse transcription polymerase chain reaction for the detection of platelet-activating factor receptor (PAFR) in follicular dendritic cells (FDCs) and B lymphocytes. Total RNA was extracted from purified FDCs or B lymphocytes, and PAFR messenger RNA (mRNA) was detected with specific primers (see "Methods"). The figure shows ethidium bromide-stained gel that is representative of two identical experiments. Lane 1 shows DNA ladder; lane 2, negative control (B lymphocytes without reverse transcriptase); lane 3, FDCs; lane 4, human tonsillar B lymphocytes; lane 5, LA350 B-lymphocyte cell line. Both sources of B lymphocytes have a much stronger mRNA signal than the FDCs have. Equal lane loading was verified by using $\beta$-actin as a housekeeping gene (not shown).

(see Figure 3), even when the mRNA was amplified to plateau by RT-PCR.9,31 The RT-PCR used in this study has been validated ${ }^{10}$ against a semiquantitatve RT-PCR and accurately reflects changes in the level of PAF mRNA. ${ }^{9}$ Although no contaminating B lymphocytes were visible in our cultures, it is possible that the trace amounts of PAFR that were detected were due to cells other than the FDCs themselves. However, to date, no other populations (apart from FDCs) isolated from tonsils propagate under the culture conditions described.

In light of our recent observations regarding PAFR expression on GC B lymphocytes, ${ }^{9}$ the action of the PAF antagonist in these studies suggests that bioactive lipid mediators may play a role in chemoattraction or GC cell organization, including the interaction of FDCs and B lymphocytes. The presence of the PAF antagonist did not diminish aggregation between $B$ lymphocytes and FDCs (data not shown). Further investigation into the link 
between FDCs and B lymphocytes may answer some heretofore unanswered questions. For example, although FDCs rescue B lymphocytes from apoptosis, the molecule that mediates this is still unknown. This effect is independent of CD40 and VLA-4 ligation, ${ }^{22}$ and FDCs do not produce cytokines, such as IL-4, that rescue B lymphocytes from apoptosis..$^{32,33}$ A novel factor secreted by FDCs, 8D6, is not involved in rescue from apoptosis and is not solely responsible for maintaining the growth of B-lymphocyte lines cultured with FDCs. ${ }^{2}$ We have demonstrated that PAF rescues the GC-like B-cell line Ramos from programmed cell death induced by B-cell receptor (BCR) ligation $^{7,17}$; the role of PAF antagonists in the rescue of apoptosis is being explored in our laboratory.

We have undertaken to determine the source of PAF in these cultures. FDCs have features of cells of myeloid-cell origin ${ }^{34}$ although some investigators have suggested an endothelial or fibroblast origin for FDCs. ${ }^{35,5}$ FDCs also have gap junctions that are areas of molecular transport for intercellular communication. ${ }^{36} \mathrm{~B}$ lymphocytes are also a source of bioactive ether lipids, including palmitoyl-2-acetoyl-sn-glycero-3-phosphocholine (PAGPC) ${ }^{28}$ The presence of this PAF analogue, which is a potent mitogen for Ig synthesis by B lymphocytes, has to date made it difficult to purify PAF in mixed FDC/B-lymphocyte cultures. The rapidity of $\mathrm{GC}$ formation ${ }^{19}$ predicts that rapidly produced or preformed chemoattractants, including chemokines or lipid mediators, are needed for direction of cellular traffic. Recent studies have established that FDCs produce monocyte chemoattractant protein- $1^{37}$ and B cell chemoattractant -1 (BCA). ${ }^{38}$ Thus, a number of candidate molecules are available for assisting the assembly of GCs. Definition of the ability of FDCs to produce chemoattractant lipid mediators such as PAF or PAGPC is important for a full comprehension of interactions that lead to GC development in lymphoid tissue.

\section{References}

1. Tew JG, Kosco MH, Burton GF, Szakal AK. Follicular dendritic cells as accessory cells. Immunol Rev 1990;117:185-211.
2. Li L, Zhang X, Kovacic S, et al. Identification of a human follicular dendritic cell molecule that stimulates germinal center B cell growth. J Exp Med 2000;191:1077-84.

3. Krenacs T, Rosendaal M. Immunohistological detection of gap junctions in human lymphoid tissue: connexin43 in follicular dendritic and lymphoendothelial cells. J Histochem Cytochem 1995;43:1125-37.

4. Kapasi ZF, Qin D, Kerr WG, et al. Follicular dendritic cell (FDC) precursors in primary lymphoid tissues. J Immunol 1998;160:1078-84.

5. Imal Y, Yamakawa M. Morphology, function and pathology of follicular dendritic cells. Pathol Int 1996;46:807-33.

6. Haley ST, Tew JG, Szakal AK. The monoclonal antibody FDC-M1 recognizes possible follicular dendritic cell precursors in the blood and bone marrow. Adv Exp Med Biol 1995;378:289-91.

7. Toledano BJ, Bastien Y, Noya F, et al. Plateletactivating factor abrogates apoptosis induced by cross-linking of the surface IgM receptor in a human B lymphoblastoid cell line. J Immunol 1997;158:3705-15.

8. Mazer B, Clay KL, Renz H, Gelfand EW. Plateletactivating factor enhances Ig production in $\mathrm{B}$ lymphoblastoid cell lines. J Immunol 1990;145:2602-7.

9. Bastien Y, Toledano BJ, Mehio N, et al. Detection of functional platelet-activating factor receptors on human tonsillar B lymphocytes. J Immunol 1999;162:5498-505.

10. Zhuang Q, Bastien Y, Mazer BD. Activation via multiple signaling pathways induces down-regulation of platelet-activating factor receptors on human B lymphocytes. J Immunol 2000;165: 2423-31.

11. Butch AW, Kelly KA, Willbanks MS, Yu X. Human follicular dendritic cells inhibit superantigen-induced T-cell proliferation by distinct mechanisms. Blood 1999;94:216-24.

12. Heinen E, Cormann N, Braun M, et al. Isolation of follicular dendritic cells from human tonsils and adenoids. VI. Analysis of prostaglandin secretion. Ann Inst Pasteur Immunol 1986; 137D:369-82.

13. Schwaeble W, Schafer MK, Petry F, et al. Follicular dendritic cells, interdigitating cells, and cells of the monocyte-macrophage lineage are the $\mathrm{C} 1 \mathrm{q}$-producing sources in the spleen. Identification of specific cell types by in situ 
hybridization and immunohistochemical analysis. J Immunol 1995;155:4971-8.

14. Hourton D, Stengel D, Chapman MJ, Ninio E. Oxidized low density lipoproteins downregulate LPS-induced platelet-activating factor receptor expression in human monocyte-derived macrophages: implications for LPS-induced nuclear factor-kappaB binding activity. Eur J Biochem 2001;268:4489-96.

15. Grouard G, de Bouteiller O, Banchereau J, Liu YJ. Human follicular dendritic cells enhance cytokine-dependent growth and differentiation of CD40-activated B cells. J Immunol 1995;155:3345-52.

16. Clark EA, Grabstein KH, Gown AM, et al. Activation of B lymphocyte maturation by a human follicular dendritic cell line, FDC-1. J Immunol 1995;155:545-55.

17. Toledano B, Bastein Y, Noya F, Mazer B. Characterization of $\mathrm{B}$ lymphocytes rescued from apoptosis by platelet-activating factor. Cell Immunol 1999;191:60-8.

18. Tew JG, Wu J, Fakher M, et al. Follicular dendritic cells: beyond the necessity of T-cell help. Trends Immunol 2001;22:361-7.

19. Qin D, Wu J, Vora KA, et al. Fc gamma receptor IIB on follicular dendritic cells regulates the B cell recall response. J Immunol 2000;164: 6268-75.

20. Wu J, Qin D, Burton GF, et al. Follicular dendritic cell-derived antigen and accessory activity in initiation of memory $\mathrm{IgG}$ responses in vitro. J Immunol 1996;157:3404-11.

21. Szakal AK, Tew JG. Follicular dendritic cells: B-cell proliferation and maturation. Cancer Res 1992;52:5554s-6s.

22. Koopman G, Keehnen RM, Lindhout E, et al. Germinal center B cells rescued from apoptosis by CD40 ligation or attachment to follicular dendritic cells, but not by engagement of surface immunoglobulin or adhesion receptors, become resistant to CD95-induced apoptosis. Eur J Immunol 1997;27:1-7.

23. Lindhout E, Lakeman A, de Groot C. Follicular dendritic cells inhibit apoptosis in human B lymphocytes by a rapid and irreversible blockade of preexisting endonuclease. J Exp Med 1995; 181:1985-95.

24. Bussolati B, Rollino C, Mariano F, et al. IL-10 stimulates production of platelet-activating factor by monocytes of patients with active systemic lupus erythematosus (SLE). Clin Exp Immunol 2000;122:471-6.

25. Fray MJ, Cooper K, Parry MJ, et al. Novel antagonists of platelet-activating factor. 1. Synthesis and structure-activity relationships of benzodiazepine and benzazepine derivatives of 2-methyl-1-phenylimidazo[4,5-c]pyridine. J Med Chem 1995;38:3514-23.

26. Casals-Stenzel J. Thieno-triazolo-1,4-diazepines as antagonists of platelet-activating factor: present status. Lipids 1991;26:1157-61.

27. Mazer B, Domenico J, Sawami H, Gelfand EW. Platelet-activating factor induces an increase in intracellular calcium and expression of regulatory genes in human B lymphoblastoid cells. J Immunol 1991;146:1914-20.

28. Mazer BD, Toledano BJ, Saririan M, Bastien Y. Dose dependent agonist and antagonist effects of the platelet-activating factor analogue 1-palmitoyl-2-acetoyl-sn-glycero-3-phosphocholine on B lymphocytes. J Allergy Clin Immunol 1998; 102:231-7.

29. Cyster JG, Ansel KM, Reif K, et al. Follicular stromal cells and lymphocyte homing to follicles. Immunol Rev 2000;176:181-93.

30. Sozzani S, Longoni D, Bonecchi R, et al. Human monocyte-derived and CD34+ cell-derived dendritic cells express functional receptors for platelet activating factor. FEBS Lett 1997;418:98-100.

31. Bastien Y, Mazer BD. Detection of the human platelet-activating factor receptor mRNA in human B lymphocytes by polymerase chain reaction on reverse transcripts (RT-PCR) [published erratum appears in Biochem Biophys Res Commun 1994;204:436]. Biochem Biophys Res Commun 1994;202:1373-9.

32. Skibinski G, Skibinska A, Deckers M, James K. Tonsil stromal-cell lines expressing FDC-like properties: isolation, characterization, and interaction with B lymphocytes. Dev Immunol 1998;6:273-84.

33. Toellner KM, Scheel-Toellner D, Sprenger R, et al. The human germinal centre cells, follicular dendritic cells and germinal centre $\mathrm{T}$ cells produce B cell-stimulating cytokines. Cytokine 1995;7:344-54.

34. Szakal AK, Kapasi ZF, Haley ST, Tew JG. A theory of follicular dendritic cell origin. Curr Top Microbiol Immunol 1995;201:1-13.

35. Muretto P. Immunohistochemical study of tonsils from newborn infants with emphasis on 
follicular dendritic reticulum cells. Eur J Histochem 1998;42:189-95.

36. Krenacs T, van Dartel M, Lindhout E, Rosendaal M. Direct cell/cell communication in the lymphoid germinal centre: connexin43 gap junctions functionally couple follicular dendritic cells to each other and to B lymphocytes. Eur J Immunol 1997;27:1489-97.
37. Husson H, Carideo EG, Cardoso AA, et al. MCP1 modulates chemotaxis by follicular lymphoma cells. Br J Haematol 2001;115:554-62.

38. Shi K, Hayashida K, Kaneko M, et al. Lymphoid chemokine B cell-attracting chemokine-1 (CXCL13) is expressed in germinal center of ectopic lymphoid follicles within the synovium of chronic arthritis patients. J Immunol 2001;166:650-5. 